ARTICLE HISTORY: July: 19, 2021 Accepted: September 12, 2021 Published: September 19, 2021

ПОВЫШЕНИЕ ЭФФЕКТИВНОСТИ СВЕТОДИОДА МЕТОДОМ НАНОСТРУКТУРИРОВАНИЯ

\author{
Ткаченко Владимир Васильевич \\ Инженер микроэлектроники и твердотельной электроники, \\ Северо-Кавказский государственныій технический университет, \\ Российская Федераиия, Ставропольский край, г.Ставрополь
}

\title{
INCREASING THE EFFICIENCY OF THE LED BY NANOSTRUCTURING
}

\author{
Tkachenko Vladimir \\ Engineer of microelectronics and solid-state electronics, \\ North-Caucasus State Technical University, \\ Russia, Stavropol region, Stavropol
}

\begin{abstract}
Аннотация. Увеличение использования светодиодных технологий в современном мире требует максимальной эффективности с минимальными затратами на производство. Совмещение нескольких технологических методов производства позволяет решить поставленную задачу.

Abstract. Increasing the use of LED technologies in the modern world requires maximum efficiency with minimal production costs. Combining several technological methods of production allows you to solve the task.

Ключевые слова: светодиод, эффективность светодиода, сапфировая подложка, эпитаксия, наноимпринтная литография.

Keywords: led, led efficiency, sapphire substrate, epitaxy, nanoimprint lithography.
\end{abstract}

Светодиодная продукция активно используется в процессе разработки $L E D$-телевизоров, дисплеев, интерьерных аксессуаров и так далее. Распространенность светодиодов тесно связана с непрерывным совершенствованием технологий модернизации, которые включают в себя наращивание слоев эпитаксии, использование корпусов и кристаллов.

Эффективность светодиода - это соотношение интенсивности светового излучения и количество затрачиваемой энергии. Данный параметр определяется такими факторами, как:

- Внутренняя квантовая эффективность - подразумевает количество фотонов, необходимых для создания электронно-дырочных пар. Определяется качеством слоя эпитаксии;

- Эффективность извлечения света - определяет количество произведенных фотонов, которые могут покинуть световой прибор;

- Электроэффективность;

- Особенности корпуса.

Традиционный взгляд на увеличение эффективности светодиодных конструкций

Высокие коэффициенты преломления полупроводников обуславливают низкие параметры светоотдачи кристаллов. Дело в том, что большая часть произведенного света отражается во внутреннем полупроводниковом пространстве: в окружающую среду распространяется мизерная часть световых излучений. Было выдвинуто множество идей об увеличении параметров светоотдачи для повышения эффективности всей светодиодной конструкции. В процессе изготовления светодиодных конструкций используется метод произвольного текстурирования и применения сапфировых подложек. Для того, чтобы выбрать наиболее правильный подход к модернизации светодиодов, следует изучить строение чипа.

Чипы светодиодных конструкций делятся на четыре категории зависимо от особенностей подложки и сочленения. Кристалл стандартного светодиода включает в себя слой $p-G a N$, расположенный в верхней части, возле $N$ и $P$-электродов, соединяющихся с корпусом через проводник. В верхней части перевернутых светодиодов располагается сапфировая подложка, в то время как $N$ и $P$-электроды сочленяются с подставкой.

Применение проводящей подложки вместо сапфировой помогает рассеивать тепло и заполучить преимущества светоотдачи. Зачастую для этого применяют технологи. «Laser-lift-off». Используется тонкопленочный светодиод. В вертикальных конструкциях $N$-электрод располагается в верхней части, в то время как $P$-электрод заменяет проводник. Одним из главных плюсов такой конструкции является вертикальный тип токотечения. В данном случае электроды располагаются в одной стороне подобно стандартным светодиодам перевернутого типа.

Методика эпитаксиального наращивания с применением металлоорганики является экономически выгодным решением, не требующим трудозатрат. В то же время, увеличение подложки и снижение пропускных параметров 
могут создавать некоторые проблемы. Например, для изготовления тонкопленочных или перевернутых светодиодов важно использовать $N$-слой $G a N$, снабженный узорами и неровностями.

Для достижения данного результата используют технику мокрого травления. Самые популярные мировые производители используют данную методику. В частности, тонкопленочные светодиоды перевернутого типа, изготовленные методом мокрого травления, обладают самыми высокими показателями светоотдачи (порядка $80 \%)$.

В процессе разработки светодиодов также применяется методика применения форматированной сапфировой подложки. В данном случае слой эпитаксия наращивают не на плоских подложках, а на узорчатых. Благодаря этому достигают следующих преимуществ:

- Увеличение внутренней квантовой эффективности;

- Свет в большей степени распространяется не внутрь, а наружу.

Увеличение полезных действий светодиодов представляет собой применение нанотехнологий, таких как NPSS (наноформирование подложки из сапфира). Согласно исследованиям, данное решение повышает эффективность светодиодных конструкций на 10-20\%. Способ модернизации включает в себя миниатюрные схемы, что сокращает время производства. Эти же особенности касаются наращивая слоев эпитаксия. Несмотря на очевидные преимущества, данная методика не используется современными производителями.

Сочетание NPSS-методик и “laser-lift-off” помогает создавать структурированные узоры на вертикальные и тонкопленочные конструкции без применения литографического оборудования с высоким разрешением. Кроме того, слой эпитаксия является более качественным, и, следовательно, помогает существенно увеличить эффективность всей светодиодной конструкции.

Создание фотонных кристаллов. Способы создания фотонных кристаллов рассматриваются как главный способ повышения светоотдачи светодиодных конструкций. Данная идея заключается в применении периодических структур, размер которых аналогичных световой волне. Благодаря этому существенно увеличивается интенсивность световых сигналов. Несмотря на широкое изучение в научных кругах, данный способ модернизации световых конструкций не обрел популярности среди изготовителей. Дело в том, что согласно исследованиям, способ улучшения является неоднозначным. Эффективность зависит от конфигурации и применения кристаллов, способов инкапсуляции и т.д. В некоторых случаях такие изделия лучше классических, в других - хуже.

Согласно сведениям Philips Lumileds, применение тонких $N$-слоев (700 нм) GaN обеспечивает наилучшие показатели светоотдачи. Способ изготовления фотонных кристаллов дает преимущество светодиодным кристаллам, содержащим минимальное количество фосфора. В состав белых светодиодных конструкций входит фосфор. В связи с этим данная методика не способна дать указанные преимущества. Дело в том, что наличие фосфора сводит на нет всю эффективность предложенной методики, поэтому ее актуальность также является сомнительной. Пропускные способности и другие преимущества способны компенсировать высокие производственные затраты. В наше время некоторые производители $L E D$-конструкций прибегают к технологии фотонных кристаллов, чтобы увеличить интенсивность светового потока. Данный способ применяется в изготовлении светодиодных конструкций повышенных мощностей, размещенных в проекторах и некоторых составляющих подсветки дисплеев.

Поверхностный плазмон. Поверхностным плазмоном называют элемент коллективного электронного колебания на металлических поверхностях. Данный элемент является самым обсуждаемым в сфере исследования нанофотонов. Он используется в коммерции для биозондирования и изучения фотонных интегрированных цепей. Существуют исследования, согласно которым поверхностный плазмон способен увеличить полезное действие солнечных батарей. Так же наблюдается значительное увеличение эффективности светодиодных конструкций. Данная методика способна напрямую влиять на электронно-дырочные пары в квантовых ямах для увеличения скорости рекомбинации излучений. Несмотря на эффективность, на практике можно столкнуться с существенной проблемой: металлический слой должен располагаться на расстоянии 100 нм от квантовой ямы. В случае, если металлические элементы располагаются в верхней части светодиодов, есть смысл утверждать, что слой $p-G a N$ должен быть тонким. Это осложняет процесс движения тока.

Наноимпринтная литография. Данная методика является одной из самых выгодных для изготовления светодиодных конструкций. Создание нано подложек является непростой задачей из-за волнообразности. Оптическая литография не является точной методикой, электронные литографические способы разработки слишком энергозатратны и медленны. Классический метод наноимпринтной литографии также является несостоятельным.

Согласно разработкам, оттиск таких подложек включает в себя два этапа. На первом этапе штамп воспроизводят на пленке из мягких полимеров. Благодаря этому формируется промежуточный полимерный штамп. Во втором случае используют штамп для переноса на подходящую подложку.

Разработки наноимпринтной литографии помогают существенно увеличить производительность и эффективность светодиодов. Существуют установки, которые создают около тридцати пластин в час. 
Заключение

Дальнейшая модернизация светодиодных конструкций основывается на великом множестве современных технологий. Исследования технологий создания фотонных кристаллов длятся уже несколько лет, однако несмотря на это, уменьшить стоимость производства пока что не удалось.

В наше время видится только один способ решения проблемы: комбинация технологий фотонных кристаллов и способов наноформирования подложек из сапфира, а также бокового наращивания слоев эпитаксия. Это является на данный момент самым успешным и перспективным методом увеличения эффективности светодиодов. Данная технология играет решающую роль в модернизации светодиодных конструкций.

\section{Список литературы:}

1. В.Е. Бугров, К.А. Виноградова. Оптоэлектроника светодиодов //Учебное пособие. 2013.С.32-155.

2. Ки Донг Ли, Роберт Сьеден, Тарбьорн Эриксон //Современная светотехника: научный Интернет - журнал. 2010. №4. C.46-48.

\section{List of literature:}

1. V. E. Bugrov, K. A. Vinogradova. Optoelectronica svetodiodov. Training manual. 2013. pp. 32-155.

2. Ki Dong Lee, Robert Sieden, Tarbjorn Erikson. Sovremennaya svetotehnica. scientific online journal. 2010. No. 4. pp. 46-48. 